\title{
Interaction of Multimodal Metaphor and Metonymy in Public Service Advertising: A Case Study*
}

\author{
Yingying Qiu \\ Foreign Language Department, Huaiyin Institute of Technology, 223003, Jiangsu, China
}

\begin{abstract}
This paper provides an analysis of a public service advertising in terms of a metaphor: A SEAT BELT IS A FAMILY, a variant of the metaphor A CAR IS A LIVING ROOM. The analysis shows how aspects of metaphors and metonymies surface in various modes and how metaphor and metonymy interaction fulfils different cognitive and persuasive roles in a multimodal genre. This paper proposes that two domains are reversible in multimodal discourse; metonymy is more fundamental than metaphor and the former serves as the basis and motivation for the latter. Because of genric features of PSA, the "embodied" aspects of metaphors and metonymies need to be universally comprehensible.
\end{abstract}

Index Terms - metaphor, metonymy, multimodal metaphor-metonymy interaction, public service advertising

\section{INTRODUCTION}

An "Embrace Life"1 video by the Sussex Safer Roads Partnership in the United Kingdom has been spreading rapidly online and achieved a million hits on its first two weeks on YouTube in 2010. The video is part of a larger "Embrace Life" campaign designed to remind individuals of the importance of wearing their seat belts. An advertising of this kind is called public service advertising (PSA). According to en.wikipedia.org, in contrast with business commercials, which are designed for the purpose of financial profits, PSAs are messages in the public interest disseminated by the media without charge, with the objective of raising awareness, changing public attitudes and behavior towards a social issue. Put it different, PSAs are seeking to raise public awareness of social issues via mass media and encourage more people to get involved in creation and interpretation of the advertisements. The metaphor "public service advertisements are also a lamp" reveals the purpose of PSAs, which is to shed light on something so that the viewers can see it.

In the context of advertising, metaphor is an integrated experience of words, images, sounds and meanings. As Kress and Van Leeuwen (1996) suggest, of the visual and verbal modes, each has "its own possibilities and limitations of meaning."(p.17) and "particular modes of communication should be seen in their environment, in the environment of all the other modes of communication which surround them, and of their functions." (p.33) Multimodal metaphors are metaphors whose target and source are each represented exclusively or predominantly in different modes. The qualification "exclusively or predominantly" is necessary because non-verbal metaphors often have targets and/or sources that are cued in more than one mode simultaneously. (Forceville \& Urios-Aparisi, 2009, p.24)

In contrast with metaphor, which can be either referential or predicative (Warren 2006), metonymy has been considered to have mostly a referential function (Lakoff and Turner, 1989, p.103). Metonymy, as an important cognitive process, not only is a rhetorical strategy but also has an important role in motivating metaphor and highlighting its mappings. Metonymy can define and represent reality and show how the product should be perceived by the audience. Barcelona (2000b) points out that metonymy is a more fundamental cognitive phenomenon than metaphor, and metaphor is very often motivated by metonymy. Actually, "the distinction between metaphor and metonymy is scalar, rather than discrete: they seem to be points on a continuum of mapping processes" (p.16). Just like Radden (2000) suggests, "the interaction of metonymy and metaphor shows that they are not two opposite poles, but two parts of a continuum from literalness to metaphor."(p.409)

This paper looks at multimodal metaphor and metonymy in the PSA "Embrace Life". It argues that a seat belt is cognitively structured by a metaphor: A SEAT BELT IS A FAMILY, a variant of the metaphor A CAR IS A LIVING ROOM. As an intangible abstraction, a seat belt, is made comprehensible by being metaphorized as a family endowed with the traits that are positively evaluated in PSA discourse: safety, warmth, protection. These metaphorical character traits of a seat belt are expressed by the interplay of verbal, aural and visual features in advertising discourse, in particular, the illustrations, music, the logo and legend.

\section{LITERATURE REVIEW}

\footnotetext{
${ }^{*}$ This paper is subsidized by the scientific research fund projects of Huaiyin Institute of Technology (HGC1119 and HGB1210).

${ }^{1}$ http://www.sussexsaferroads.gov.uk/safer-for-all-drivers/embrace-life-seatbelt-campaign.html
} 
Charles Forceville (1996) has extended studies on metaphor into the realm of multimodality and has exerted a profound influence on metaphor studies. Forceville \& Urios-Aparisi's collection Multimodal Metaphor (2009) shows all the latest research results at abroad. All scholars are primarily concerned with the respects like the value and effect of modality as well as its interaction, dynamic interplay of metaphor and metonymy, stylistic dimensions of metaphor as well as the cultural and the embodimental foundation of metaphor.

The chapters of the book are organized by the modes playing a role in the identification and interpretation of the metaphors studied. And it takes into account the genre to discourses: advertisements, political cartoons, comics, animation, musical compositions, oral conversations and lectures, feature films.

Since advertising has been the subject of a number of studies on pictorial metaphor, it is not surprising advertising which integrates with the modes of language, visuals and sound/music attracts most scholarly attention.

In this book, Koller (2009) charts how the logos, visuals, and layouts that are used to create companies' corporate identities and they often require or invite the construal of metaphors. Tying in with the pervasive BRANDS ARE LIVING ORGANISMS metaphor, visual elements often subtly encourage the inference of positive corporate qualities that are not necessarily verbalized. Identifying the metaphorical mechanisms deployed to achieve this goal points the way to how the inevitably biased nature of companies' self-portraits can be critically examined.

Caballero (2009) is part of an ongoing research project which is partly based on an impressive corpus of 12,000 wine tasting notes in professional journals, and here takes into account Spanish and French wine advertisements as well. An important issue in the paper is the difficulty of the "translation" of these hardly theorized modes of taste and smell into a shared "vocabulary" of pictures and words. Another pertinent issue is the role of the cultural background governing both the choice of source domain in purely verbal metaphors describing wines and the choice of visuals in the advertisements.

Urios-Aparisi (2009) discusses instances of Spanish television commercials. He addresses how Forceville's multimodal metaphor interacts with metonymical mappings, and applies the taxonomy to multimodal advertising texts, identifying their cognitive value and communicative strategies within this genre.

Yu (2009) provides an in-depth analysis of a single educational message broadcast on Chinese Central Television (CCTV) in terms of two conceptual metaphors whose purely verbal varieties have often been discussed: LIFE IS A JOURNEY and LIFE IS A STAGE. He shows how aspects of these metaphors, which in some passages are "blended", surface in various modes. In several scenes, moreover, other conceptual metaphors such as UNDERSTANDING IS SEEING and SUCCESSFUL IS UP are shown to play a role, as well as a range of metonymies. The analysis makes clear that whereas thanks to the visuals, the "embodied" aspects of the metaphors are presumably universally comprehensible, many details can only be fully appreciated by viewers aware of specific Chinese myths and beliefs.

In China, four papers published in Foreign Language Research in 2011 symbolize the beginning of multimodal metaphor study. Studies on multimodal metaphor can be divided into two categories. One is the theoretical study. Zhao (2011) presents a brief literature review over multimodal metaphor studies in reference to Forceville \& Urios-Aparisi's collection (2009), covering its origin, development, focus, achievements, challenges and prospects as well. Xie (2011) presents some key issues based on the explanation of Forceville \& Urios-Aparisi's theory. Firstly, Lakoff's Embodied Philosophy could account for the philosophical basis of multimodal metaphor. Secondly, due to various genres and modes, two domains are possibly reversible. Thirdly, compared to verbal metaphor, the representations are likely to be multidimensional and informative, which could make a deep impression on the readers with the help of concrete images. Finally, the findings of the experiment display that verbal texts in a multimodal metaphor could exert influence on nonverbal texts. Li \& Shi (2010) attempts to discuss the possibility and necessity of multimodal metaphor studies in foreign languages as the future research direction in applied linguistics.

Another is the empirical study which applies the multimodal metaphor theory to different discourses. Zhang \& Zhan (2011) show us the essence of multimodal metaphor and metonymy and their cognitive model. They analyze the dynamic construal and verbal-visual relation of multimodal metaphor and multimodal metonymy in advertising discourses. Pan (2011) conducts a cognitive study of two political cartoons with its generic features in order to analyze interplay between multimodal metaphor and multimodal metonymy and their dynamic construal and then accounts for choices of source domain and target domain. Zhao \& Su (2010) focus on dynamic process of integrative meaning construction of the metaphorical multimodal discourse. Based on the generalization of features of multimodal metaphor, they propose that the integrative meaning of metaphorical multimodal discourse derives from a complex conceptual blending involved with interplay of metonymy and metaphor. It reveals that the cognitive approach helps to explain the psychological motivations for the persuasive and aesthetic function.

As we can observe, with reference to multimodal metaphor theory, all studies analyze business commercials, there are few about non-commercial advertising, in particular, PSA. This paper is part of the attempt to refine the present theories of conceptual metaphor/metonymy, their dynamic interaction, and their different functions in the interplay.

\section{SYNOPSIS OF THE ADVERTISING}

Embrace Life is an award winning short British public information film made for the Sussex Safer Roads Partnership (SSRP) about the importance of wearing seat belts. Here is a synopsis of the advertising under discussion. 
At the beginning, with the playing of the slow-tempo music, a close-up shot focuses on a hand turns an imaginary ignition key and a foot operating an imaginary foot pedal. A mother and a daughter watch the father from the sofa in their living room which is decorated in orange and yellow hue. The father with a relaxed smile is playacting at driving a car and steers an imaginary wheel. The father turns to look at them, and the daughter responds to him with a big smile. However, as he turns back, he sees some sort of danger approaching. Meanwhile, the daughter's smile disappears. He grimaces and turns the wheel to the left to avoid the oncoming threat. The daughter rushes to him when realizing he is in danger. Her hands (a close-up shot) embrace him around the waist. His wife follows and put her arms around his upper body. All of a sudden, the audio shifts from the slow-tempo music to a fast-tempo one. The impact occurs, and the man is violently thrown in his seat; his legs jolt out and kick over a table with a bowl holding small metallic decorations. The bowl is thrown upwards and the metal decorations shower down. The daughter and mother successfully restrain the father, and he recovers, bringing his arms up to embrace his family who have saved him. (The music comes back to the slow-tempo one.) The legend "Embrace Life" in orange appears on the left of the screen, followed by "Always wear your seat belt" in white. The picture then dissolves into a view of the legend. As the film fades to black, the triangular grey, orange and blue Embrace Life logo is shown above that of the Sussex Safer Roads Partnership.

The name of the advertising, Embrace Life, reflects its focus on life rather than the death and injury often associated with car crashes. A lot of the "Embrace Life" campaigns focus on the more graphic and horrific outcomes of accidents, while this advertising doesn't take a conventional route to shock and scare the audience, rather it brings the audience in on the conversation of road safety, specifically seat belts.

\section{ANALYSIS}

In this section, I analyze the advertising to show that its persuasive and aesthetic effects are achieved through, among other things, nonverbal and multimodal manifestations of a metaphor: A SEAT BELT IS A FAMILY, a variant of the metaphor A CAR IS A LIVING ROOM. While the latter is realized almost exclusively through moving images, accompanied by musical sounds, the former one is manifested visually and aurally, as well as verbally through the legend: "Embrace Life. Always wear your seat belt." Other than these two metaphors, the advertising also contains several metonymies which motivate and constitute the metaphors.

\section{A. Multimodal Metonymy}

The advertising has deployed a lot of metonymies to achieve its persuasive and aesthetic effects. The camera focuses on a man turning an imaginary ignition key, operating an imaginary foot pedal and steering an imaginary wheel with a relaxed smile. This image is easily identifiable with driving by the metonymy MANNER OF ACTION FOR THE ACTION. This driving is accompanied by metonymical music (from slow-tempo music to fast-tempo one) and images(from a relaxed smile to his grimacing and turning the wheel to the left) which can be associated with driving conditions. The representation of a seat belt follows three metonymies: EMBLEM FOR PRODUCT ("Embrace Life" logo for A Seat Belt), EFFECT FOR CAUSE (Safety for Wrapping Arms) and PART FOR WHOLE(Arms for A family). These metonymies under analysis are all integrated into the metaphor A FAMILY IS A SEAT BELT which is analyzed in next section. All the metonymies are summarized in Table 1.

TABLE 1

METONYMIES IN THE ADVERTISING

\begin{tabular}{|l|l|l|}
\hline Metonymy type & Metonymy in advertising & Explanation \\
\hline $\begin{array}{l}\text { MANNER OF ACTION FOR THE } \\
\text { ACTION }\end{array}$ & $\begin{array}{l}\text { Turning an imaginary ignition key, } \\
\text { operating an imaginary foot pedal and } \\
\text { steering an imaginary wheel for Driving }\end{array}$ & Visual representation of the action \\
\hline EMBLEM FOR PRODUCT & "Embrace Life" logo for A Seat Belt & $\begin{array}{l}\text { Visual representation of } \\
\text { the product }\end{array}$ \\
\hline EFFECT FOR CAUSE & Safety for Wrapping Arms & $\begin{array}{l}\text { Highlighted consequence of wrapping } \\
\text { arms }\end{array}$ \\
\hline PART FOR WHOLE & Arms for A family & The salient parts of the whole \\
\hline
\end{tabular}

Another metonymy to be discussed is DEFINING PROPERTY FOR CATEGORY. The legend "Embrace Life. Always wear your seat belt", the triangular grey, orange and blue Embrace Life logo and the click sound of fastening a seat belt manifest the category (seat belt) visually and aurally as well as verbally, summarized in Table 2 .

TABLE 2

MODES IN A METONYMY

\begin{tabular}{|l|l|l|l|l|}
\hline Figure & Components & Visual & Words & Sound \\
\hline Metonymy & TARGET & $\begin{array}{l}\text { Always wear your seat } \\
\text { belt }\end{array}$ & \\
\cline { 2 - 5 } & SOURCE & Embrace Life logo & & $\begin{array}{l}\text { The click sound of } \\
\text { fastening a seat belt }\end{array}$ \\
\hline
\end{tabular}

As we can observe, this advertising features good examples of metonymic references in various modes. Metonymies, 
in this case, are mostly referential with respect to driving and a family, but these metonymies can create further implicit meanings by the audience's knowledge of the importance of safety and a family. Besides these components, there is one obvious absence in the visual representations: that of the seat belt which is directly addressed in the words and indirectly in visual images. During the advertising, seat belt is not mentioned until it is metonymically implied by the sound "click", the logo and the legend "wear seat belt".

\section{B. Multimodal Metaphor}

In non-verbal and multimodal metaphors, the signals that cue metaphorical similarity between two phenomena are different, and bound to differ depending on the mode(s) in which the metaphorical terms are represented. Forceville (2009) summarizes three metaphorical similarities: perceptual resemblance, filling a schematic slot unexpectedly and simultaneous cueing. Perceptual resemblance can only function as a trigger in the case of monomodal metaphors: only a visual representation can perceptually resemble another visual representation; only a sound can perceptually resemble another sound in volume, timbre, or pitch. In the case of visual resemblance, "there is a larger range of choices: two things can resemble one another because they have the same size, color, position, posture, texture, materiality, etc."(p.31) In the advertising, the daughter's wrapping arms are similar to the lap belts and the positioning of the mother's arms reflects the position of the upper seat belt strap for the driver. That is, their wrapping arms resemble the two parts of a seat belt. Therefore, the metaphor WRAPPING ARMS ARE A SEAT BELT is manifested based on perceptual resemblance, which is a monomodal metaphor. Another similarity comes from filling a schematic slot unexpectedly. It means "placing a thing in a certain context may strongly, even inescapably, evoke a different kind of thing, namely the thing for which the given context is the natural or conventional place."(p.31) In Embrace Life, when the father is playacting at driving a car, the target domain_—which in advertising usually is identical with, or metonymically connected to, arms__ occurs in a place where one expects a seat belt. We encounter wrapping arms from the typical gestalts or schemas of a seat belt. Here the metaphor WRAPPING ARMS ARE A SEAT BELT comes into being based on filling a schematic slot unexpectedly.

In the advertising, another metaphor is explicitly represented in the images: A CAR IS A LIVING ROOM. The source domain is shown in the first image, while the target is never mentioned, but it is metonymically implied by the father's playacting. The target and source domains in the metaphor establish symmetrical correspondences between various items within the two domains, such as those shown in Table 3 . The living room represents the feelings of safety and protection from the "outer" world, which is similar to the feelings their car brings. The house represents a safety area where you're normally surrounded by your loved ones, and the car can be an extension of that. The small metallic decorations of the room graphically represent the shattered windscreen glass and metal fragments generated during a car accident.

TABLE 3

A CAR IS A LIVING ROOM

\begin{tabular}{|l|l|}
\hline SOURCE & TARGET \\
\hline LIVING ROOM & CAR \\
\hline SAFETY AND PROTECTION FROM OUTSIDE & SAFETY AND PROTECTION FROM OUTSIDE \\
\hline BE SURROUNDED BY THE LOVED ONES & BE ACCOMPANIED BY FAMILY AND FRIENDS \\
\hline SMALL METALLIC DECORATIONS & $\begin{array}{l}\text { SHATTERED WINDSCREEN GLASS AND METAL } \\
\text { FRAGMENTS }\end{array}$ \\
\hline THE DAUGHTER'S AND MOTHER'S WRAPPING ARMS & A SEAT BELT \\
\hline
\end{tabular}

The visual mode could be divided into several submodes such as color or facial expression. The submodes are building blocks of each mode. The soft colors of the living room in an orange and yellow hue and smile of the father represent he is relaxed in good driving condition and the family is full of love. The hue and colors are stereotypically warm and thus represent the feeling of safety that a seat belt is supposed to give and associate to the metaphor SOFT COLOR IS WARMTH and, thus, to the metaphor AFFECTION IS WARMTH and, if that is the case, the color submode would integrate experiences of love and safety with safe driving. The last screen fades to black and the triangular grey, orange and blue Embrace Life logo is shown. The contrast between warm colors and cold colors acts as a warning to the audience of safe driving. Each mode and submode associates a seat belt with the main metaphor A SEAT BELT IS A FAMILY and relates it to sensations of safety and warmth, and relaxation. The modes and their association with different components in the metaphor in this commercial are listed in Table 4.

\section{Interaction of Multimodal Metaphor and Metonymy}

In the dynamics of a TV advertising, metonymical mappings do not only substitute for or represent the target, but expand the interpretation of metaphorical mappings. The metaphor WRAPPING ARMS ARE A SEAT BELT, which highlights wrapping arms as it can resemble a seat belt, with the help of the metonymy PART FOR WHOLE(Arms for A family), allows for the metaphor A FAMILY IS A SEAT BELT to be enacted. The protection of a family to a person is like that of a seat belt to a person. The metaphor makes the metonymy progress towards mappings and tries to convey additional meanings such as emotional representation and didactic effects in the cognitive environment of the audience.

The metonymy EFFECT FOR CAUSE(Safety for Wrapping Arms) and legend "Embrace Life" motivate another metaphor A SEAT BELT IS A FAMILY. As a family is associated with safety and warmth, the PSA enacts the 
quintessential feature of seat belt by identifying and making a seat belt as wrapping arms. The importance of a seat belt to a person is similar to that of a family (far from arms) to a person. The two metaphors mentioned above show that two domains of a metaphor are reversible. The reversibility depends on the multipurpose of the communication or action.

In conclusion, the metaphor A SEAT BELT IS A FAMILY is elaborated through a complex interaction of modal techniques and metonymies. The modes and their association with different components in the metaphor and metonymy are listed in Table 4.

TABLE 4

A SEAT BELT IS A FAMILY

\begin{tabular}{|l|l|l|l|l|}
\hline Figure & Components & Visual & Words & Sound \\
\hline Metaphor & TARGET & The logo of seat belt & $\begin{array}{l}\text { The click sound of } \\
\text { fastening a seat belt }\end{array}$ \\
\cline { 2 - 5 } & SOURCE & $\begin{array}{l}\text { A family: metonymical } \\
\text { implied by wrapping } \\
\text { arms(PART FOR WHOLE) } \\
\text { Submode 1: } \\
\text { facial expression of the } \\
\text { family } \\
\text { Submode 2: } \\
\text { Soft color of the living room }\end{array}$ & Legend "Embrace life" & \\
& & & \\
\hline
\end{tabular}

\section{Selection of Source and Target Domain}

The advertising roots the concept of wearing a seat belt firmly in the family domain so that it could be viewed by anyone of any age. Children are as important as opinion formers within their family and a child takes a pivotal role in relaying the message that it's not only yourself that's impacted if something unfortunately goes wrong, but also family and friends too. The choices of family and kids as source or target domain in a traffic safety public service advertising can be explained by Maslow's hierarchy of needs (Maslow, 1943). Maslow used the terms physiological, safety, belongingness and love, esteem, self-Actualization and self-Transcendence needs to describe the pattern that human motivations generally move through. Safety and Security needs include: personal security, financial security, health and well-being and safety net against accidents/illness and their adverse impacts. Love and belonging, the third level of human needs, are especially strong in childhood. The advertising created to raise awareness of the importance of wearing a seat belt meets safety need and the choices of family and kids as source or target domain meet love need.

The advertising was primarily designed for and its spread has been almost entirely through the internet. Another key aspect to the storytelling is that Embrace Life to be non-language specific, so that the message wouldn't become lost when viewed by visitors whose first language is not English. The lack of dialogue means Embrace Life is accessible to all viewers, no matter what nationality. To summarize, just as Forceville (2007, p.27) puts it, "metaphors whose targets and sources are cued wholly or partly via visual, sonic, or musical cues, may be understood, maybe in rudimentary fashion only, by an audience unfamiliar with the language of the country from which the metaphorical representation originates. Apart from their greater degree of comprehensibility, metaphors drawing on images, sounds, and music also, I submit, have a more intense, immediate emotional impact than verbal ones."

Because of genric features of PSA, the "embodied" aspects of metaphors and metonymies need to be universally comprehensible. The daughter is wearing fairy wings as angel wings, symbolizing a guardian angel. Belief in both the East and the West is that guardian angels serve to protect whichever person God assigns them to, and present prayer to God on that person's behalf. In such special genre, the cultural or group-specific environment within which metaphors occur can be avoided in order to guarantee the construal and interpretation of multimodal metaphors.

\section{CONCLUSION}

PSAs are dynamic discourses in which all modes can contribute to multimodal metaphors either in the source domain or the target domain. The modes and submodes in the advertising are structured around a clearly defined target, and the need to persuade or represent the target in a positive light. All elements addressed in the advertising contribute to the need for interaction of metaphors and metonymies which follows cognitive patterns which restrict and define their design and persuasion.

Metonymy has two functions. The first is to identify those entities which are to be transferred from the two domains. The second is to represent the target for the metaphor in a way that can be realistic for the metaphorical representation and motivate the message of the advertising.

In multimodal discourses, two domains of a metaphor are reversible. The reversibility depends on the multipurpose of the communication or action. If the target audience of PSAS are not cultural or group-specific community, the creative team need to ground the metaphors in common experience and make full use of each mode and its submodes to elicit audience's attention and emotions. 


\section{REFERENCES}

[1] Barcelona, A. (2000b). Introduction: The cognitive theory of metaphor and metonymy. In Antonio Barcelona (ed.), Metaphor and Metonymy at the Crossroads: A Cognitive Perspective (pp.1-28). Berlin/New York: Mouton de Gruyter.

[2] Caballero, R. (2009). Cutting across the senses: Imagery in winespeak and audiovisual promotion. In Forceville, C. \& UriosAparisi, E. (eds), Multimodal Metaphor (pp.119-143). Berlin/New York: Mouton de Gruyter.

[3] Forceville, C. (1996). Pictorial Metaphor in Advertising. London/New York: Routledge.

[4] Forceville, C. (2007). Multimodal metaphor in ten Dutch TV commercials. Public Journal of Semiotics, 1, 19-51.

[5] Forceville, C. \& Urios-Aparisi, E. (2009). Multimodal Metaphor. Berlin/New York: Mouton de Gruyter.

[6] Koller, V. (2009). Brand images: Multimodal metaphor in corporate branding messages. In Forceville, C. \& Urios-Aparisi, E.(eds), Multimodal Metaphor (pp.119-143). Berlin/New York: Mouton de Gruyter.

[7] Kress, G. \& van Leeuwen. (1996). Reading Images: The Grammar of Visual Design. London/New York: Routledge.

[8] Lakoff, G. \&Turner, M. (1989). More than Cool Reason: A Field Guide to Poetic Metaphor. Chicago: University of Chicago Press.

[9] Li Yi \& Shi Lei. (2010). Multimodal metaphors in foreign language teaching as future research direction. Computer-Assisted Foreign Language Education, 133(5), 47-49.

[10] Maslow, A.H. (1943). A theory of human motivation. Psychological Review, 50(4), 370-396.

[11] Pan Yanyan. (2011). Multimodal metaphor and multimodal metonymy in political cartoons. Foreign Language Research, 125(1), 11-15.

[12] Radden, G. (2000). How metonymic are metaphors? In Antonio Barcelona (ed.), Metaphor and Metonymy at the Crossroads: A Cognitive Perspective (pp.93-108). Berlin/New York: Mouton de Gruyter.

[13] Urios-Aparisi, E. (2009). Interaction of multimodal metaphor and metonymy in TV commercials: Four case studies. In Forceville, C. \& Urios-Aparisi, E. (eds), Multimodal Metaphor (pp.95-117). Berlin/New York: Mouton de Gruyter.

[14] Warren, B. (2006). Referential Metonymy. Lund: Almqvist and Wiksell.

[15] Yu, N. (2009). Nonverbal and multimodal manifestation of metaphors and metonymies: A case study. In Forceville, C. \& Urios-Aparisi, E. (eds), Multimodal Metaphor (pp.119-143). Berlin/New York: Mouton de Gruyter.

[16] Zhang, Hui \& Zhan Weiwei. (2011). The dynamic construal of multimodal metaphor and multimodal metonymy in commercials. Foreign Language Research, 125(1), 16-23.

[17] Zhao, Xiufeng \& Su Huiyan. (2010). Cognitive meaning construction of metaphorical multimodal discourse - blending on the interplay of multimodal metonymy and multimodal metaphor. Journal of University of Science and Technology Beijing (Social Sciences Edition), 26(4), 18-24.

[18] Zhao, Xiufeng. (2011). New development of conceptual metaphor studies: Multimodal metaphor. Foreign Language Research, $125(1), 1-10$

Yingying Qiu was born in Jiangsu, China in 1981. She got the MA of Arts at Nanjing Normal University, China in 2011. She was currently a lecturer in Foreign Language Department in Huaiyin Institute of Technology, Jiangsu, China. Her research interest is cognitive linguistics. 